\title{
A New Proposed Pressure and Stress Transducer
}

\author{
S. M. Abbas \\ Private Researcher
}

\begin{abstract}
This paper proposes a new 2D active transducer for sensing and measuring pressure and stress measurands using micromachined technology. The sensor used here depends on the variations of a parallel plate capacitor with one of the plates is tied while the other is tied from its ends only left to change shape under pressure or stress waves directed in any direction .The capacitors are connected to the emitters of an EC multivibrator ( ECMV ) to change its frequency as capacitor value changes. The capacitor rods are arranged in parallel and the two sets are arranged at 90 degrees to each other to detect 2D variations in the measurands. The output of this transducer is an ECMV output which can be altered to any signal shape as required .
\end{abstract}

\section{General Terms}

Sensors ,nano-structures ,micromaching, active transducers.

\section{Keywords}

Active sensors ,Active transducers ,nano-structures

\section{INTRODUCTION}

Many signal processing applications require on-chip reliable sensors compatible with integrated circuitry, fabricated using standard technology .Several microsensors were fabricated in standard CMOS or bipolar technology to measure mechanical ,magnetic field ,temperature ,radiation ,and chemical measurands. Generally sensors can be divided into two groups : active sensors which gives output signal as voltage, current, or frequency, and passive sensors which respond to an external effect by modification of their basic parameters . Many sensor structures were introduced for measuring pressure or stress ,but not to indicate its direction. The transducer described here gives direction of the wave effect and indicate if its in $\mathrm{x}$ - or $-\mathrm{x}$ - direction .The output is an ECMV waveform . O.Akar,etc [1], uses a capacitor a and gold-electro plated coil to sense pressure through changing frequency in 1D. J. Eom etc [2] , using deformation of polymeric diaphragm to sense pressure . K. Ya ,etc [3] , uses effect of external pressure on magnetic properties of hertospin crystal to sense pressure .Finally I. Pekark .etc [4] , uses carbon nanotubes array and

MEMS membrane to sense pressure . All of the mentioned methods and other methods which are not mentioned here give the indication of the existence of pressure or stress waves but do not give its direction, while the method described here gives the direction in 2D and if its in forward or reverse.

\section{DESIGN OF THE TRANSDUCER}

The new transducer consists of two sets of capacitors, each set compose of two nano rods with same dimensions made of same material as shown in (fig 1).One of them is fixed entirely against any change in shape while the other have its ends are fixed only and middle part is left free to change shape if subjected to pressure or stress waves. When its shape has changed ,the capacitance formed from parallel combination of the two rods will change consequently, and the resonant frequency of ECMV will change as well as shown in ( fig 2). This transducer can give the direction of the pressure or the stress, since the effect of these waves will deform the partially left to move rod of the capacitor either to be nearer to or farther from the fixed rod of the capacitor ,in other words increasing or decreasing value of capacitance as shown in (fig 3 ) .If the effect of the waves is in -x-direction ,then the capacitor shape will as shown in (fig 2), while if its in $\mathrm{x}$-direction, then the capacitor shape will be as shown in (fig 3). In order to sense the effect waves in y- and - ydirection, the capacitor design will be as shown in (fig 4) .The same as described for $\mathrm{x}$-direction if the effect of waves is in $\mathrm{y}$-direction or in $-\mathrm{y}$-direction

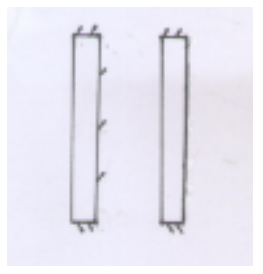

Fig 1: Nano rods for $x$-direction

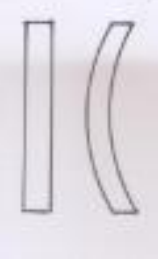

Fig 2 : Nano rods after- $x$-perssure

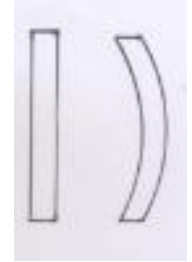

Fig 3: Nano rods after $x$-perssure

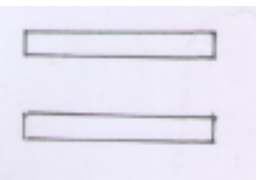

Fig 4: Nano rods for y-direction

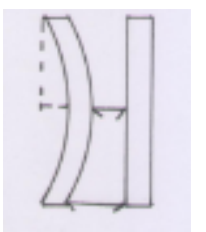

Fig 5: simple modelling of capacitance 


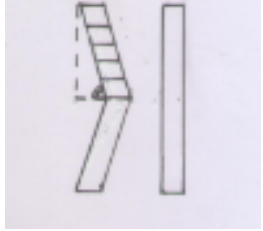

Fig 6: Model used to calculate capacitance change

\section{CALCUlations OF THE CAPACITOR}

To calculate the capacitance, 1 st order model will be used as shown in (fig 5), normal capacitance value is

$$
\mathrm{C}=€ . \mathrm{A} / \mathrm{X}
$$

Where $€$ is the permittivity of the dielectric material between .. the plates, $\mathrm{A}$ is the area of the plates and $\mathrm{X}$ is the distance between the plates

Now after the deformation of the moving plate, $\mathrm{X}$ will change as the moving plate will be shaped as shown in (fig 5) .Then

$$
\mathrm{X}^{*}=\mathrm{X}-\Delta \mathrm{X},
$$

And $\Delta \mathrm{X}$ will change along the length of the moving rod as shown in (fig 5) .To calculate $\Delta \mathrm{X}, \tan \alpha$ as shown in (fig 6) is given by

$$
\tan \alpha=\mathrm{L} / 2 / \Delta \mathrm{X}
$$

where $\mathrm{L}$ is the length of the rod, and the new distance between the plates is given by

$$
\mathrm{X}^{*}=\mathrm{X}-\mathrm{L} / 2 / \tan \alpha
$$

Dividing the rod length into 10 subsections , then 10 readings for subsections capacitor are needed as shown in fig (5), each subsection with $\Delta \mathrm{X}$ given by

$$
\Delta \mathrm{X}^{*}=\mathrm{ZL} / 10 / \tan \alpha
$$

Where $\mathrm{Z}=1,2,3,4$, and 5 according to what section is being calculated.

And thus the distance between the plates is given by

$$
\mathrm{X}^{*}=\mathrm{X}-\Delta \mathrm{X}^{*}
$$

Then the capacitance value is

$$
\mathrm{C}=2 \mathrm{C} 1+2 \mathrm{C} 2+2 \mathrm{C} 3+2 \mathrm{C} 4+2 \mathrm{C} 5
$$

Where $\mathrm{C} 1=\mathrm{C} 10, \mathrm{C} 2=\mathrm{C} 9, \mathrm{C} 3=\mathrm{C} 8, \mathrm{C} 4=\mathrm{C} 7$, and $\mathrm{C} 5=\mathrm{C} 6$

And the final equation for calculating the capacitance is

$$
\begin{array}{r}
\mathrm{C}=2 € \\
\mathrm{X} 4 *+\mathrm{A} 5 / \mathrm{X} 5 *\}
\end{array}\{\mathrm{A} 1 / \mathrm{X} 1 *+\mathrm{A} 2 / \mathrm{X} 2 *+\mathrm{A} 3 / \mathrm{X} 3 *+\mathrm{A} 4 /
$$

Where each A can be calculated from

$$
\mathrm{A}=(\mathrm{L} / 10) . \mathrm{W}
$$

Where $\mathrm{w}$ represents width of the capacitor plates. The resultant capacitor value will be used across emitters of an ECMV with a frequency of

$$
\mathrm{F}=\mathrm{I} 1 / 4 \mathrm{C} 1 \mathrm{VBE}
$$

Thus any change in $\mathrm{C} 1$ will vary $\mathrm{F}$. This equation is for sensing pressure or stress waves in $\mathrm{x}-$ and $-\mathrm{x}$ - directions , where $\mathrm{C} 1$ will increase if waves effect is in $\mathrm{x}$-direction and $\mathrm{C} 1$ will decrease if waves effect in $-\mathrm{x}$ - direction on the assumption that two ECMV circuits are used for $\mathrm{x}$ - and $\mathrm{y}-$ directions .

\section{RESULTS}

To show some results for this sensor, an assumption will be made here that wave effect was so that the moving capacitor plate length was increased by $10 \%$ of its original length which is by assumption also is $10 \mathrm{~nm}$ as shown in fig (6), the original distance between the plates is $10 \mathrm{~nm}$, and the width of the plates is $10 \mathrm{~nm}$ as well, then the angle $(\alpha)$ will be 72.24 , $\tan \alpha$ is 3.123 , thus

$$
\begin{aligned}
\Delta X^{*} 1 & =\{\mathrm{L} / 10\} / \tan 72.24=0.320 \mathrm{~nm} \\
\Delta X^{*} 2 & =\{2 \mathrm{~L} / 10\} / \tan 72.24=0.64 \mathrm{~nm} \\
\Delta X^{*} 3 & =\{3 \mathrm{~L} / 10\} / \tan 72.24=0.96 \mathrm{~nm} \\
\Delta X^{*} 4 & =\{4 \mathrm{~L} / 10\} / \tan 72.24=1.28 \mathrm{~nm} \\
\Delta X^{*} 5 & =\{5 \mathrm{~L} / 10\} / \tan 72.24=1.60 \mathrm{~nm}
\end{aligned}
$$

And the corresponding distances between the plates will be

$$
\begin{aligned}
& X * 1=10-0.32=9.68 \mathrm{~nm} \\
& X * 2=10-0.64=9.36 \mathrm{~nm} \\
& X * 3=10-0.96=9.04 \mathrm{~nm} \\
& X * 4=10-1.28=8.72 \mathrm{~nm}
\end{aligned}
$$

$\mathrm{X} * 5=10-1.60=8.4 \mathrm{~nm}$

Area of each subsection is $\{\mathrm{L} / 10\} . \mathrm{W}=\{10 / 10\} .10=10$ $\mathrm{nm} 2$,

Then the deformed capacitor value will be $10 / 8.4$

$C^{*}=2 €\{10 / 9.68+10 / 9.36+10 / 9.04+10 / 8.72+$

$$
=2 €\{5.543\}
$$

While the original capacitance value is

$$
\mathrm{C}=2 €\{10.10 / 10\}=2 €\{10\}
$$

Nearly half capacitance value means doubling the frequency of the ECL gate. This simple calculations indicate the sensibility of this sensor in $\mathrm{x}-,-\mathrm{x}-, \mathrm{y}-$, and $-\mathrm{y}$ - directions . If the assumed change in capacitance is $1 \%$, then the deformed capacitance value will be

$$
\mathrm{C}^{*}=2 €\{5.2244\}
$$

Which means a great change in capacitance value increasing sensor ability. If the calculations conducted on -x direction the results will be as given, for the $10 \%$ case, the capacitance value will be

$$
C^{*}=2 €\{4.5667\}
$$

And for the $1 \%$ case ,

$$
\mathrm{C}^{*}=2 €\{4.7978\}
$$

Which gives a difference between $\mathrm{x}$ and $-\mathrm{x}$ directions of more than $17 \%$ in capacitance value

\section{CONCLUSION}

A new active 2D pressure and stress transducer is proposed with high sensibility and simple design , which uses standard micro-machined technology . The output of this active sensor is an ECMV waveform which can be changed easily into any other form . 


\section{REFERENCES}

[1] O.Akar.etc.2001.A wireless batch scaled absolute capacitance pressure sensor.Sensors and Actuaters .vol 95.issue $1.29-38$.

[2] J.Eom,etc .2015.Fiber optic fabry-perot pressure sensor based on lensed fiber and polymeric diaphragm.Sensors and Actuators .vol 225.25-32.
[3] K.Ya ,etc.A hetrospin pressure sensor. $\mathrm{j}$ of materials .no.30.

[4] I,Pekark ,etc.2015.MEMS carbon nanotube field emission pressure sensor with simplified design .Sensors J .IEEE .vol15.no 3. 